\section{$\underset{\text { hommes }}{\text { \& migrations }}$}

\section{Hommes \& migrations}

Revue française de référence sur les dynamiques

migratoires

1315 | 2016

Ondes de choc

\title{
Karim Miské, N’appartenir
}

Paris, Viviane Hamy, 2015, 88 p., 12,50€

\section{Catherine Guilyardi}

\section{Q OpenEdition \\ 12 Journals}

\section{Édition électronique}

URL : http://journals.openedition.org/hommesmigrations/3759

DOI : 10.4000/hommesmigrations.3759

ISSN : 2262-3353

\section{Éditeur}

Musée national de l'histoire de l'immigration

\section{Édition imprimée}

Date de publication : 1 juillet 2016

Pagination : 150-151

ISBN : 978-2-919040-36-0

ISSN : $1142-852 X$

\section{Référence électronique}

Catherine Guilyardi, «Karim Miské, N’appartenir », Hommes \& migrations [En ligne], 1315 | 2016, mis en ligne le 01 juillet 2016, consulté le 24 septembre 2020. URL : http://journals.openedition.org/

hommesmigrations/3759; DOI : https://doi.org/10.4000/hommesmigrations.3759 


\section{Karim Miské}

N'appartenir

Paris, Viviane Hamy, 2015, 88 p., 12,50€

"Au commencement, il y a la honte. " C'est la première phrase de la première scène qui ouvre le livre et raconte un souvenir enfoui dans la mémoire de l'auteur, surgi

vingt-cing ans plus tard dans le cabinet d'un psy. Ce jour-là, son grand-père ne se conduit pas comme d'habitude. Autour de la famille réunie, cet homme adoré, modèle masculin en l'absence d'un père séparé et voyageur, délire, mais il dit la vérité pour la première fois. "Boum! écrit Miské. Tu as neuf ans et demi, toute la famille est là. Ta famille blanche dans laquelle tu grandis depuis toujours en faisant comme si toi aussi tu l'étais, en une étrange danse d'évitement du miroir. " Alors que l'enfant tente de calmer son grand-père, il reçoit en pleine face " un mot dur comme un uppercut et venimeux comme une morsure de vipère". Le mot révèle la douleur enfouie par cette famille depuis le mariage de leur fille avec " cet Arabe ", dix ans plus tôt, et dont Karim est le fruit. Dans ce texte écrit dans un souffle, il n'y a pas de chapitre, juste ces mots en majuscules qui rythment le flot de l'écriture. Les majuscules crient ce que l'auteur a bien dû admettre. "OH TOI, LE BÂTARD ! " dit le grand-père. Et le silence retombe. "COMME SI DE RIEN N'ÉTAIT ", reconnaît l'auteur.

N'appartenir est un beau livre sur la fatalité puis la volonté de ne pas appar- tenir à un groupe en particulier. Karim Miské n'est ni blanc, ni noir, ni catholique, ni musulman, ni communiste, ni esclavagiste, comme le lui intiment ses lignées maternelle et paternelle.

Fils unique d'un Mauritanien, ambassadeur, et d'une mère française, fille d'excolons, il sera élevé seul par sa famille blanche. "J'habite une étrangeté. Inquiétante, parfois. Ne jamais être exactement celui-là : the Arab in the mirror. Ni celuici : le Français dans ma tête. Drôle d'état. Le mien depuis toujours. N'être inclus dans rien, n'habiter aucune catégorie solidement établie. Perpétuelle oscillation au bord du gouffre. Incessant questionnement existentiel. "

À l'école, il est le "fellaga " parce qu'il a la tête de celui que la France hait pendant la guerre d'Algérie, mais il n'est pas algérien. Ses camarades le savent. Ils sont mal à l'aise parce qu'ils ne peuvent pas le mettre dans une case. En CM2, Karim est fasciné par " ce type, l'élève modèle de la classe, ni le meilleur ni le plus intelligent. Seulement l'archétype d'une espèce qui ne se sait pas en voie de disparition, et qui me fascine alors. Blanc, français, parents non divorcés. Catholiques. Le gars ne doute pas. Incroyable comme il ne doute pas. " Et Karim se met à envier ces certitudes. "Race, religion, politique, je suis dehors, lui dedans. (...) Quand tu te fatigues à les porter. Ces putains de différences. Ça doit être tellement bon. Se fondre dormir. "Être ou ne pas (en) être ? À la maison, Karim est pourtant entouré de certitudes : sa mère et ses amis soutiennent les fellagas et embrassent le communisme. Sa mère choisit celui d'Enver Hoxha, le dirigeant albanais. Karim se rend plusieurs fois 
dans le pays avec sa mère. Ils sont reçus comme des rois. C'est là qu'il découvre le mensonge. Le culte de la personnalité du despote de ce petit État totalement fermé au reste du monde contredit le communisme généreux et empreint d'espérance auquel veut tellement croire sa mère. Comment appartenir quand toute allégeance inconditionnelle est un mensonge? Jeune adulte, il se rend dans le pays de son père. D'abord séduit par cette famille mauritanienne respectée, il accepte même de jouer le rôle d'intercesseur avec Dieu, lui qui ne croit pas. II embrasserait bien cet héritage quand il se rend compte que sa grand-mère est esclavagiste et que son père n'a jamais osé lutter contre cette " tradition".
Appartenir n'est pas simple quand on ne peut pas se mentir à soi-même, et quand on aime la liberté. N'appartenir est une force. Et s'il faut appartenir alors ce sera " au pays de la littérature, celui qu'avaient cartographié Bradbury et Truffaut. Fahrenheit 451 : un monde où les livres sont impitoyablement détruits et où une poignée de résistants obstinés les apprennent par coeur, devenant des hommes-livres, les porteurs du meilleur de l'humanité. "Alors Karim Miské se met à écrire pour enfin " $\left(S^{\prime}\right)$ APPARTENIR ».

Chez le même éditeur, paraîtra en novembre 2016 un roman graphique : S'appartenir, scénario de Karim Miské et dessin d'Antoine Silvestri.

Catherine Guilyardi

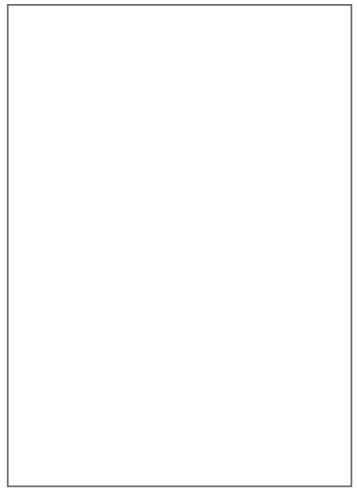

Éloi Laurent Nos mythologies économiques

Paris, Les liens qui libèrent, 2016, 106 p., $12 €$

Éloi Laurent tire à boulets rouges sur un mythe devenu le plus petit dénominateur commun d'une " pensée » qui court les bistrots, les tables dominicales, les émissions télévisées et autres tribunes politiciennes : le chiffre fait roi, le chiffre érigé en instance supérieure, l'économie devenue l'alpha et l'oméga de toute action et politique, et qui rabaisse la vie à deux interrogations : " combien ça coûte? ", " combien ça rapporte ? ". II fut un temps où cette attitude relevait du vulgaire. Aujourd'hui, on la sert ad nauseam, sous couvert de "responsabilité », de "réalisme » et d' "impératif ". "Du coup, qui veut paraitre important (...) fait l'économiste. »

II y a urgence, car l'économie " est une mythologie qui désenchante le monde " : exit la part rêvée et poétique de l'existence, effacées les couleurs d'un monde indocile à la triste logique statistique. L'étonnant est que cette " tutelle du chiffre ", cette économie devenue "la grammaire de la politique ", est un sophisme, "une mythologie " qui se (et nous) trompe doublement : en perdant de vue l'essentiel et en (nous) faisant 